\title{
NOTE
}

\section{The Diurnal Rhythm of Plasma Aldosterone, Plasma Renin Activity, Plasma Cortisol and Serum Growth Hormone and Subnormal Responsiveness of Aldosterone to Angiotensin-II in the Patients with Normotensive Acromegaly}

\author{
SHUICHI ICHIKAWA, TETSUo SAKAMAKI, \\ SACHIKo TONOOKA, AND YoshIRO SUGAI \\ 2nd Department of Internal Medicine \\ Gunma University School of Medicine, Maebashi 371
}

\begin{abstract}
Synopsis
The diurnal rhythm of plasma aldosterone concentration (PA), plasma renin activity (FRA), plasma cortisol (PC) and serum growth hormone (GH) were examined in 5 cases of normotensive acromegaly and the results were compared with the observations in normal subjects. Moreover, the response of PA to angiotensin-II infusion was studied in 6 cases of normotensive acromegaly.

A normal diurnal rhythm with the lowest values in the evening or midnight and the highest values in the morning was observed in 3 of 5 cases in PA and 3 of 4 cases in PC. On the other hand, no apparent rhythm of GH was observed in any cases and that of PRA in 4 of 5 cases. Although there was a significant positive correlation between PA and PC, no significant correlation was demonstrated between PA and PRA. The response of PA to angiotensin-II infusion was significantly suppressed in normotensive acromegaly as compared to the normal subjects in spite of normal levels of PRA except for 1 case.

The above observations were interpreted to suggest that the aldosterone regulation system is slightly altered in a certain number of patients with normotensive acromegaly in contrast to the normal subjects in which PRA is the main contributing factor. The low PA and suppressed response of PA to angiotensin-II infusion may suggest the defective action of angiotensin-II infusion on the adrenal gland.
\end{abstract}

Hypertension is a rather common complication of acromegaly (Balzer and McCullagh, 1959 ; Souadjian and Shriger, 1967) and some of the patients have primary aldosteronism (Dluhy and Williams, 1969; Strauch et al., 1972; Strauch et al., 1973). Although there are several reports on the renin-angiotensinaldosterone system in acromegaly, the results are controversial and the roles of this system in the development of hypertension are not entirely clear until the present time. Strauch and his coworkers (1972) have reported that the renin-angiotensin-aldosterone system is

Received for publication June 25, 1975. normal in normotensive acromegaly both in the basal state and after sodium deprivation and in the upright position. On the other hand, Cain and his coworkers $(1970,1972)$ have reported that both the basal level and the response to sodium restriction of the aldosterone excretion rate are significantly depressed in normotensive acromegaly as compared to the normal subjects, although the upright plasma renin activity and its response to sodium restriction remain within normal limits. They have suspected that some common derangement of sodium, volume and aldosterone homeostasis might be present in acromegaly as 
in some of the essential hypertension pointed out by Williams et al. (1970). According to Werning and coworkers (1970), the aldosterone excretion rate is normal in normotensive acromegaly while plasma renin activity remains rather low and shows only a very slight increase in the upright position.

The present study was performed in order to investigate whether the abnormalities of the renin-angiotensin-aldosterone system were associated in normotensive acromegaly. For this purpose, investigations were made on the diurnal rhythm of plasma aldosterone, plasma renin activity and plasma cortisol in normotensive acromegaly, and the results were compared with those in normal subjects. Moreover, the response of plasma aldosterone rise following angiotensin-II infusion was studied.

\section{Materials and Methods}

The materials consisted of 7 cases of acromegaly with normal blood pressure, 4 males and 3 females between 31 and 61 years of age, and 9 normal volunteers between 19 and 38 . All the cases were hospitalized during the study.

The blood pressure of the patients with acromegaly ranged from 104 to $118 \mathrm{mmHg}$ systolic and from 60 to $80 \mathrm{mmHg}$ diastolic, respectively. The fasting serum growth hormone levels in these patients were $37.5 \mathrm{ng} / \mathrm{ml}$ or more, but other pituitary hormone levels including TSH, LH and FSH were within normal limits. Two cases, case 13 and 14, were considered to be active acromegaly according to the criteria proposed by Hamwi and his coworkers (1960), while the remaining 5 was diagnosed as inactive. Case $11,13,15$ and 16 have received external pituitary radiation previously. Obvious suprasellar extension of the pituitary tumor was demonstrated in case 13, who was later operated on. The liver and renal function tests in all cases were within normal range. Mild sodium restricted diets $(80 \mathrm{mEq} /$ day) were started 3-7 days prior to the study of diurnal rhythm. The angiotensin-II infusion test was performed under liberal salt intake except in the case $10,11,12$ and 13 who were under sodium restriction in the same way mentioned above.

The diurnal rhythm study was performed in supine position except at each meal time for less than 15 minutes. Ten to $15 \mathrm{ml}$ of blood samples were obtained every 4 hours from noon to the next noon without indwelling needle but by serial venipancture so as not to disturb sleep. The blood samples were centrifuged immediately and kept frozen until analyzed. The patients and the normal controls were kept in supine position for one and a half hours at least before the angiotensin infusion test. The test was started at $3 \mathrm{p} . \mathrm{m}$. in every case. Five hundred mililiters of $5 \%$ glucose solution containing $0.5 \mathrm{mg}$ of angiotensin-II (Hypertensin CIBA) was slowly infused intravenously and the blood pressure was kept $20-30 \mathrm{mmHg}$ in diastolic above the control level. The infusion time ranged from one and a half to 2 hours.

The GH, PC, PRA and PA were measured by radioimmunoassay. Commercially available radioimmunoassay kits of Dainabot Radioisotope Laboratory, Daiichi Radioisotope Laboratory and CEACEN-SORIN were used for GH, PC and PRA determination, respectively. The details of the method for the measurement of PA was previously described (Ichikawa et al., 1974). A chromatographic separation of aldosterone by Sephadex LH-20 column was performed after the extraction with dichloromethane, and PA was determined by radioimmunoassay. In order to simplify the separation, 1, 4-diaminoanthraquinone was applicated as a marker dye on Sephadex LH-20 column.

Statistical analysis was performed as described by Snedecor and Cochran (1967), while partial correlation coefficient was calculated by the method described by Freund (1960).

\section{Results}

\section{Diurnal rhythm of $P R A, P A$ and $P C$}

(1) Normal subjects (Table 1, Fig. 1): The diurnal rhythm study was made in 5 normal subjects. An obvious biphasic diurnal pattern of PRA, PA and PC with the lowest values between 4 p.m. and midnight and the highest at 4 a.m. or 8 a.m. was observed in all of the normal subjects. There was a significant partial correlation between PRA and PA (PC being held constant, $\mathrm{r}=+0.525$, $\mathrm{p}<0.005$ ) and between PA and PC (PRA being held constant, $r=+0.393, p<0.05)$. The partial correlation between PRA and PC was not statistically significant. No obvious diurnal rhythm was demonstrated in serum sodium and potassium levels.

(2) The patients with acromegaly (Table 2, Fig. 2): The study of diurnal rhythm 
Table 1. Diurnal rhythm of plasma renin activity (PRA), plasma aldosterone (PA), plasma cortisol (PC), serum sodium $(\mathrm{Na})$ and potassium $(\mathrm{K})$ levels in normal subjects.

\begin{tabular}{|c|c|c|c|c|c|c|c|c|c|c|}
\hline Case number & & Age & $\operatorname{Sex}$ & Noon & 4 p.m. & 8 p.m. & $\mathrm{MN}$ & 4 a.m. & 8 a.m. & Noon \\
\hline \multirow{4}{*}{1} & \multirow{4}{*}{22} & \multirow{4}{*}{$\mathbf{M}$} & PRA & 5.4 & 3.0 & 3.6 & 6.6 & 9.4 & 7.7 & 4.6 \\
\hline & & & PA & 102 & 108 & n.d. & n.d. & 204 & 164 & 69 \\
\hline & & & PC & 5.6 & 4.7 & 1.4 & n.d. & 5.9 & 9.0 & 6.6 \\
\hline & & & PRA & 4.1 & 3.8 & 3.7 & 4.6 & 7.1 & 5.7 & 5.5 \\
\hline \multirow[t]{3}{*}{2} & \multirow[t]{3}{*}{19} & \multirow[t]{3}{*}{$\mathbf{M}$} & PA & 58 & 56 & 22 & 26 & 130 & 79 & 87 \\
\hline & & & PC & 1.6 & 3.4 & n.d. & n.d. & 6.3 & 3.8 & 8.5 \\
\hline & & & PRA & 6.8 & 5.7 & 8.0 & 10.5 & 11.6 & 10.5 & 7.9 \\
\hline \multirow[t]{3}{*}{3} & \multirow[t]{3}{*}{23} & \multirow[t]{3}{*}{$\mathbf{M}$} & PA & 69 & 44 & 39 & 156 & 265 & 101 & 146 \\
\hline & & & PC & 2.8 & 1.5 & n.d. & 2.8 & 8.8 & 11.0 & 7.3 \\
\hline & & & PRA & 7.3 & 4.2 & 3.6 & 6.1 & 9.3 & 10.1 & 13.1 \\
\hline \multirow[t]{3}{*}{4} & \multirow[t]{3}{*}{21} & \multirow[t]{3}{*}{$\mathbf{M}$} & PA & 109 & 66 & 41 & 45 & 91 & 309 & 134 \\
\hline & & & $\mathrm{PC}$ & 10.4 & 4.8 & 3.0 & 4.1 & 10.1 & 5.1 & 7.8 \\
\hline & & & PRA & 4.5 & 2.8 & 3.8 & 13.3 & 8.0 & 5.3 & 4.4 \\
\hline \multirow[t]{4}{*}{5} & \multirow[t]{4}{*}{24} & \multirow[t]{2}{*}{$\mathbf{M}$} & PA & 72 & 64 & 35 & 73 & 126 & 96 & 77 \\
\hline & & & $\mathrm{PC}$ & 5.7 & 2.5 & 1.8 & n.d. & 1.7 & 7.6 & 5.0 \\
\hline & & & & 5.6 & 3.9 & 4.5 & 8.2 & 9.1 & 7.9 & 7.1 \\
\hline & & & PRA & 0.6 & 0.5 & 0.8 & 1.4 & 0.7 & 1.0 & 1.4 \\
\hline \multirow{6}{*}{ Mean \pm SE } & & & & 82 & 68 & 29 & 62 & 163 & 150 & 103 \\
\hline & & & PA & 9 & 10 & 5 & 23 & 28 & 38 & 14 \\
\hline & & & & 5.2 & 3.4 & 1.6 & 2.0 & 6.6 & 7.3 & 7.0 \\
\hline & & & PC & 1.4 & 0.6 & 0.3 & 0.6 & 1.3 & 1.1 & 0.5 \\
\hline & & & & 143.3 & 140.0 & 137.0 & 142.6 & 140.6 & 141.1 & 141.5 \\
\hline & & & $\mathrm{Na}$ & 4.3 & 5.7 & 4.8 & 4.7 & 2.4 & 1.9 & 2.8 \\
\hline \multirow[t]{2}{*}{ Mean \pm SE } & & & & 4.2 & 4.2 & 4.3 & 4.2 & 4.1 & 4.2 & 4.2 \\
\hline & & & $\mathrm{K}$ & 0.2 & 0.3 & 0.5 & 0.2 & 0.2 & 0.2 & 0.2 \\
\hline
\end{tabular}

n.d.: Undetectable $\{$ PA: less than $10 \mathrm{pg} / \mathrm{ml}$

PRA $(\mathrm{ng} / \mathrm{m} l / \mathrm{hr}) \quad \mathrm{PA}(\mathrm{pg} / \mathrm{m} l) \quad \mathrm{PC}(\mu \mathrm{g} / 100 \mathrm{~m} l) \quad \mathrm{Na}(\mathrm{mEq} / l) \quad \mathrm{K}(\mathrm{mEq} / l)$

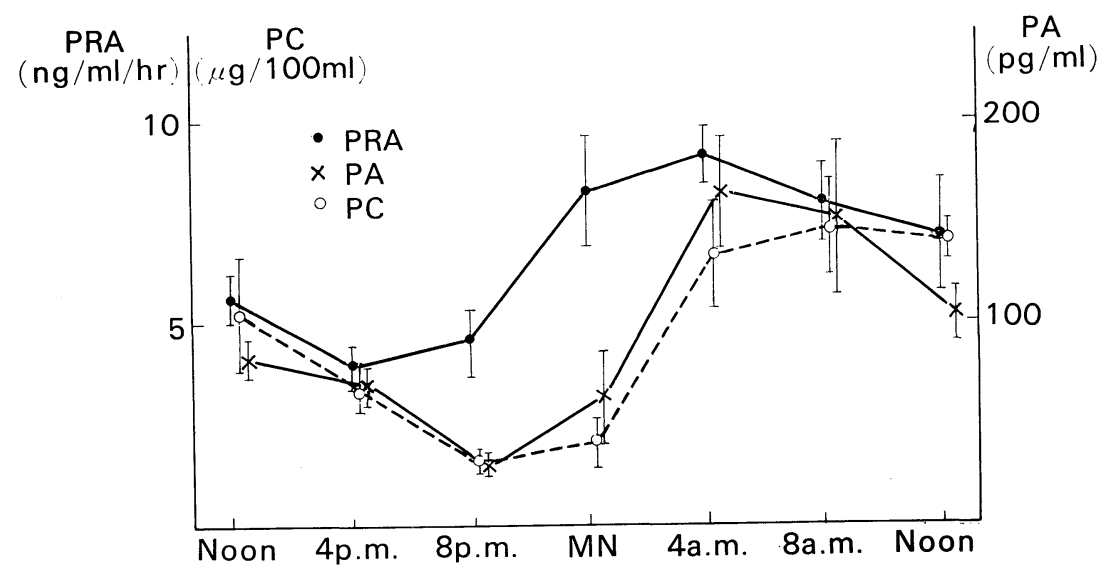

Fig. 1. Diurnal rhythm of plasma renin activity (PRA), plasma aldosterone (PA) and plasma cortisol (PC) in normal subjects (Mean $\pm \mathrm{SE}$ ). 
was performed in 5 cases. An apparent diurnal rhythm in PRA similar to normal subjects was not observed in 4 cases. A normal diurnal rhythm in PA was demonstrated in 3 cases (case 10,11 and 12). The diurnal PA levels were relatively low in case 10,13 and 14 as compared to the normal subjects, while in case 11 and 12, the levels were normal and high, respectively. The diurnal rhythm study of PC was made in 4 cases and a normal diurnal rhythm was observed in 3 (case 10,11 and 12), but the rhythm was not obvious in case 13. The interrelationship of PRA, PA and PC was studied in 4 cases, for $\mathrm{PC}$ was not determined in case 14 . A significant positive partial correlation was demonstrated only between PA and PC $(r= \pm 0.700, p<0.001)$.

The $\mathrm{GH}$ values were remarkably high in all cases. Although a little fluctuation was observed in 4 cases, no apparent diurnal rhythm in GH was demonstrated. Diurnal rhythm of serum sodium and potassium levels was not demonstrated in 2 cases studied.

\section{Angiotensin-II infusion test}

The results were shown in Tables 3 and 4 and Fig. 3. The values of PA before angiotensin-II infusion were slightly higher than in normal subjects. However, the difference was not statistically significant.

In normal subjects, PA was almost doubled following 90 minutes infusion of angiotensin-II. The increasing rate of PA in 4 cases studied was $104 \pm 16 \%$ (Mean士 SE). A fairly normal increase in PA was observed in 3 of 6 cases of acromegaly, almost the same change in the remaining 3 cases of acromegaly, and in those cases PA values remained almost unchanged, too. The increasing rate of $\mathrm{PA}$ at 90 minutes was $36 \pm 16 \%$ (Mean $\pm S E$ ) in acromegaly, and which was significantly lower than in the normal subjects. The pressor dose of

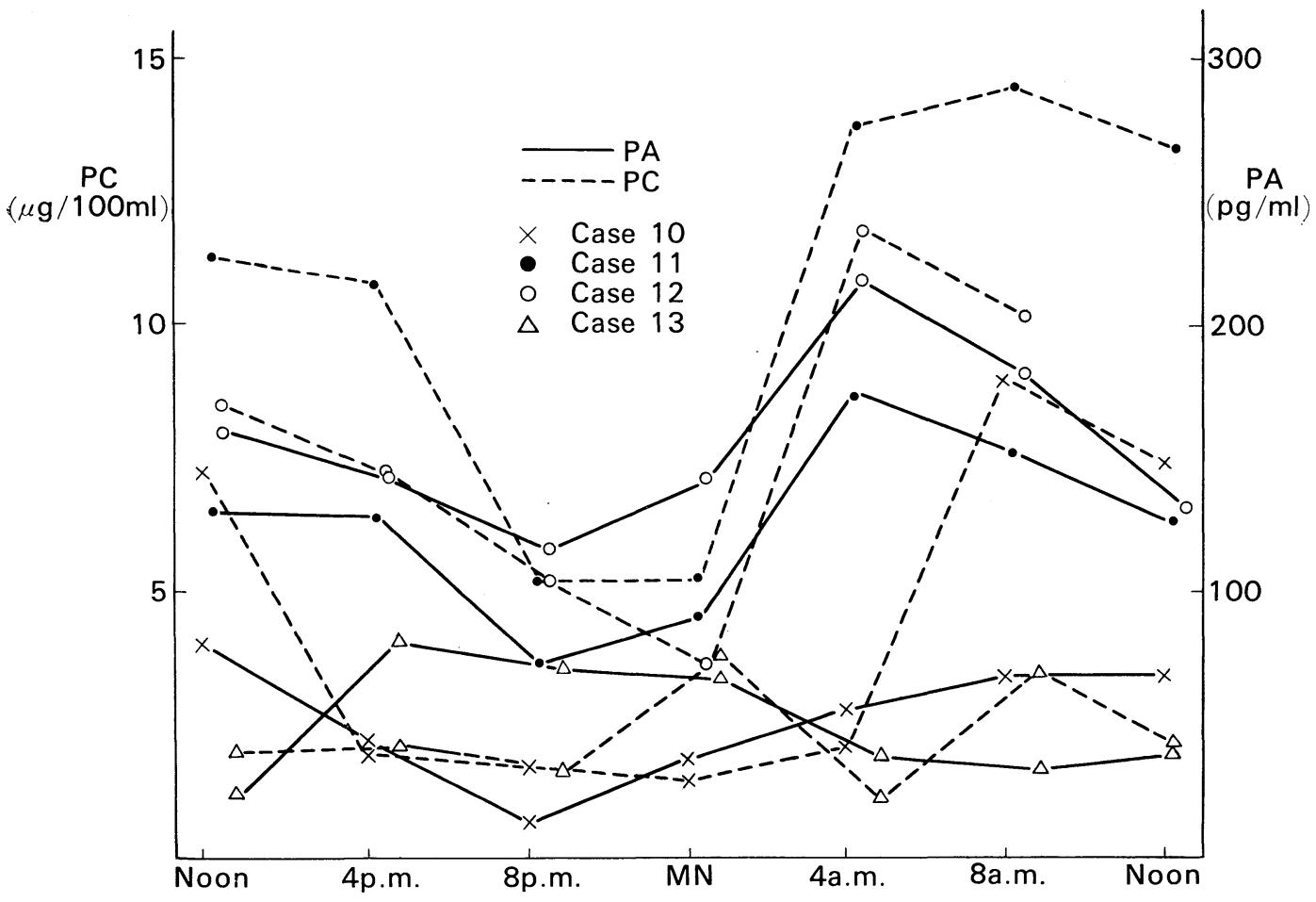

Fig. 2. Diurnal rhythm of plasma aldosterone (PA) and plasma cortisol (PC) in normotensive acromegaly 
Table 2. Diurnal rhythm of plasma renin activity (PRA), plasma aldosterone (PA), plasma cortisol (PC), serum growth hormone $(\mathrm{GH})$, serum sodium $(\mathrm{Na})$ and potassium $(\mathrm{K})$ levels in normotensive acromegaly.

\begin{tabular}{|c|c|c|c|c|c|c|c|c|c|c|}
\hline Case number & & Sex & Age & Noon & 4 p.m. & 8 p.m. & $\mathrm{MN}$ & 4 a.m. & 8 a.m. & Noon \\
\hline \multirow{4}{*}{10} & \multirow{4}{*}{$\mathbf{M}$} & \multirow{4}{*}{47} & PRA & - & 1.2 & 0.5 & 0.5 & 0.3 & 0.4 & 0.2 \\
\hline & & & PA & 80 & 44 & 14 & 38 & 57 & 69 & 69 \\
\hline & & & $\mathrm{PC}$ & 7.2 & 2.0 & 1.7 & 1.5 & 2.1 & 9.0 & 7.4 \\
\hline & & & $\mathrm{GH}$ & 38.1 & 33.1 & 34.3 & 37.5 & 38.7 & 37.5 & 52.0 \\
\hline \multirow{5}{*}{11} & \multirow{4}{*}{ M } & \multirow{4}{*}{45} & PRA & 1.1 & 2.8 & 2.8 & 3.8 & 3.3 & 4.1 & 3.5 \\
\hline & & & PA & 130 & 129 & 74 & 90 & 176 & 153 & 127 \\
\hline & & & $\mathrm{PC}$ & 11.3 & 10.8 & 5.2 & 5.2 & 13.8 & 14.5 & 13.4 \\
\hline & & & $\mathrm{GH}$ & 59 & 80 & 80 & 75 & 80 & 63 & 51 \\
\hline & & & PRA & 2.1 & 1.4 & 1.9 & 2.6 & 3.4 & 4.0 & 3.0 \\
\hline \multirow{5}{*}{12} & \multirow{5}{*}{$\mathrm{F}$} & \multirow{5}{*}{42} & PA & 160 & 143 & 117 & 142 & 219 & 183 & 135 \\
\hline & & & PC & 8.5 & 7.2 & 5.2 & 3.7 & 11.9 & 11.2 & - \\
\hline & & & $\mathrm{GH}$ & 61.7 & 61.7 & 51.4 & 68.4 & 62.8 & - & 73.3 \\
\hline & & & $\mathrm{Na}$ & - & 144.9 & 141.8 & 143.6 & 148.7 & 142.5 & 144.6 \\
\hline & & & $\mathrm{K}$ & - & 4.3 & 4.2 & 4.4 & 4.5 & 4.3 & 4.8 \\
\hline \multirow{4}{*}{13} & \multirow{4}{*}{$\mathrm{F}$} & \multirow{4}{*}{3} & PRA & 4.8 & 4.3 & $4 \cdot 0$ & 4.0 & 4.2 & 4.1 & 4.1 \\
\hline & & & PA & 25 & 82 & 71 & 68 & 39 & 33 & 40 \\
\hline & & & PC & 2.0 & 2.1 & 1.6 & 3.8 & 1.1 & 3.5 & 2.1 \\
\hline & & & GH & 80 & 80 & 80 & 80 & 80 & 80 & 80 \\
\hline \multirow{6}{*}{14} & \multirow{6}{*}{$\mathbf{M}$} & & PRA & 2.7 & 1.3 & 1.1 & 1.4 & 0.6 & 3.1 & 2.8 \\
\hline & & \multirow{5}{*}{31} & PA & n.d. & 13.2 & n.d. & n.d. & n.d. & n.d. & 17.8 \\
\hline & & & PC & - & - & - & - & - & - & - \\
\hline & & & $\mathrm{GH}$ & 55 & 72 & 75 & 64 & 64 & 67 & 60 \\
\hline & & & $\mathrm{Na}$ & 138.6 & 141.1 & 140.4 & 135.2 & 137.7 & 136.5 & 138.4 \\
\hline & & & $\mathrm{K}$ & 5.2 & 4.6 & 4.7 & 4.9 & 4.3 & 4.8 & 5.2 \\
\hline 15 & $\mathbf{M}$ & 62 & - & & & & & & & \\
\hline 16 & $\mathrm{~F}$ & 65 & - & & & & & & & \\
\hline
\end{tabular}

n.d.: undetectable (PA : less than $10 \mathrm{pg} / \mathrm{ml}$ )

-: undetermined

PRA $(\mathrm{ng} / \mathrm{m} l / \mathrm{hr}) \quad \mathrm{PA}(\mu \mathrm{g} / 100 \mathrm{ml}) \quad \mathrm{PC}(\mu \mathrm{g} / \mathrm{m} l) \quad \mathrm{GH}(\mathrm{ng} / \mathrm{m} l) \quad \mathrm{Na}(\mathrm{mEq} / \mathrm{l}) \quad \mathrm{K}(\mathrm{mEq} / \mathrm{l})$

Table 3. Angiotensin-II infusion test on plasma aldosterone level in normal subjects

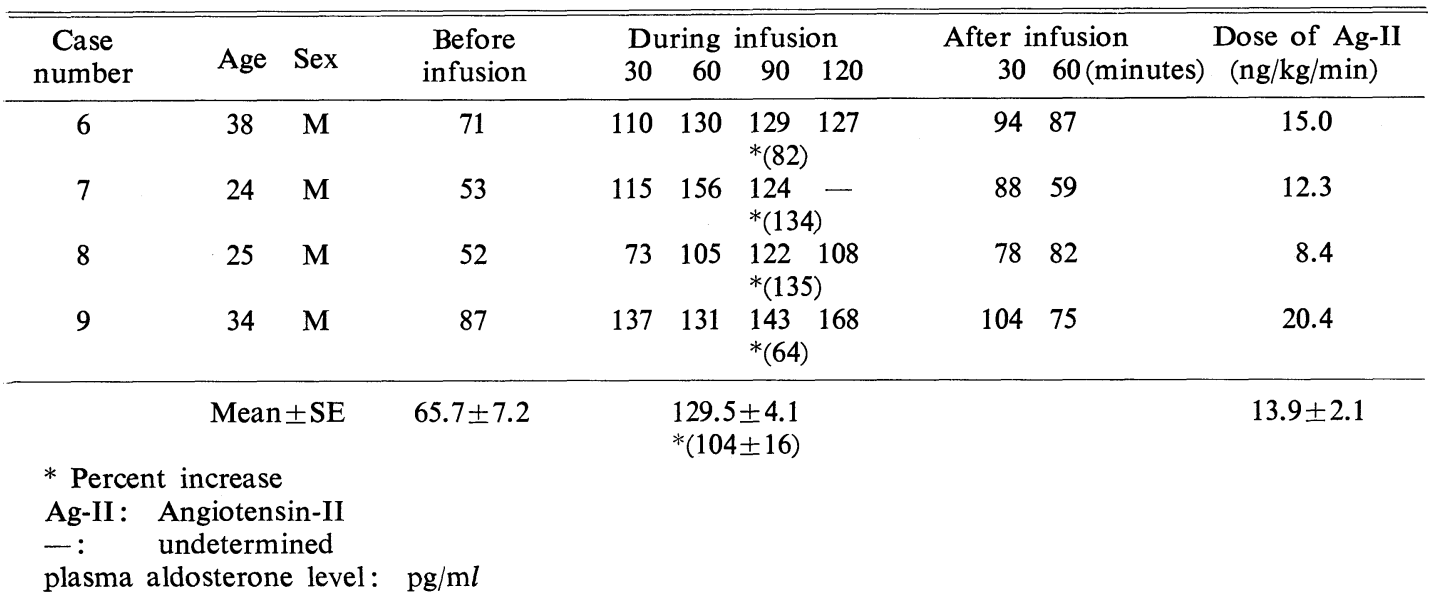


angiotensin-II to maintain the diastolic pressure $20-30 \mathrm{mmHg}$ above the control level in the normal subjects and the patients with acromegaly was $13.9 \pm 2.1$ and $17.2 \pm 4.8 \mathrm{ng} / \mathrm{kg} / \mathrm{min}$ (Mean $\pm \mathrm{SE}$ ), respectively. The difference between the values was not significant.

\section{Discussion}

The diurnal rhythm in PRA, PA and PC in normal subjects has been well investigated (Gordon et al., 1966; Katz et al., 1972; Vagnucci et al., 1974; Grim et al., 1974). In agreement with the previous reports, the present investigation on the normal subjects showed obvious diurnal rhythm in PRA, PA and $\mathrm{PC}$ with the lowest values in the evening or midnight and the highest values in the morning. Because PA was more closely correlated with PRA than PC, it is adequately conceivable that the diurnal rhythm of PA in the normal subjects is mainly mediated

Fig. 3. Effect of angiotensin-II on plasma aldosterone in normal subjects and the patients with normotensive acromegaly figured by percent increase at 90 minutes following pressor dose of angiotensin-II (Mean $\pm \mathrm{SE})$.

\section{Percent increase}

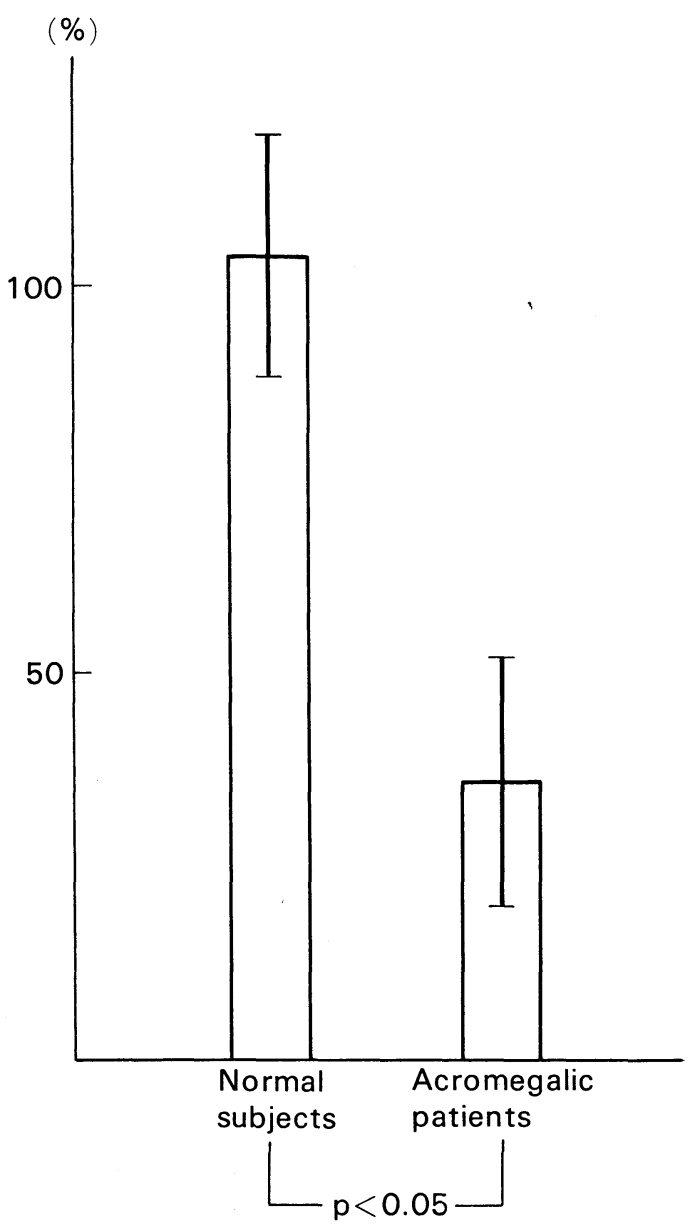

Table 4. Angiotensin-II infusion test on plasma aldosterone level in normotensive acromegaly

\begin{tabular}{|c|c|c|c|c|c|c|c|c|}
\hline \multirow{2}{*}{$\begin{array}{c}\text { Case } \\
\text { number }\end{array}$} & \multirow{2}{*}{$\begin{array}{c}\text { Bufore } \\
\text { infusion }\end{array}$} & \multicolumn{4}{|c|}{ During infusion } & \multicolumn{2}{|c|}{ After infusion } & \multirow{2}{*}{$\begin{array}{c}\text { Dose of } \mathrm{Ag} \text {-II } \\
(\mathrm{ng} / \mathrm{kg} / \mathrm{min})\end{array}$} \\
\hline & & 30 & 60 & 90 & 120 & 30 & 60 (minutes) & \\
\hline 10 & 62 & 60 & 65 & $\begin{array}{c}51 \\
*(-18\end{array}$ & 71 & 57 & 52 & 10.0 \\
\hline 11 & 120 & 129 & 174 & $\begin{array}{l}111 \\
*(-8)\end{array}$ & 144 & 171 & 167 & 25.0 \\
\hline 12 & 160 & 268 & 259 & $\begin{array}{l}300 \\
*(88)\end{array}$ & - & - & 143 & 40.0 \\
\hline 13 & 111 & 174 & 199 & $\begin{array}{l}168 \\
*(51)\end{array}$ & 172 & 116 & 125 & 5.0 \\
\hline 14 & - & - & - & - & - & - & - & \\
\hline 15 & 76 & 107 & 101 & $\begin{array}{l}101 \\
*(33)\end{array}$ & - & 91 & 72 & 10.4 \\
\hline 16 & 72 & 130 & 134 & $\begin{array}{l}124 \\
*(72) \\
\end{array}$ & - & 90 & 92 & 13.3 \\
\hline Mean \pm SE & $100 \pm 12.8$ & & $\begin{array}{l}142 \\
*(3\end{array}$ & & & & & $17.2 \pm 4.8$ \\
\hline
\end{tabular}

* Percent increase Ag-II : Angiotensin-II - : undetermined plasma aldosterone level: pg/ml 
by PRA. However, it is postulated that ACTH is also playing an important role in diurnal rhythm in PA, because there is a significant partial correlation between PA and PC. Williams and his coworkers (1972) have started that ACTH might be affecting both renin release and adrenal glucocorticoids secretion in nomal subjects. Moreover, Katz and coworkers (1975) have recently reported that the common determinant for ACTH and aldosterone might exist in spine men by measuring hormones every 10 or 30 minutes and by interdiction of $\mathrm{ACTH}$ production by dexamethasone. They have suggested that the lack of constant correlation of PA with PRA implies that in supine men renin is not the most important factor in control of aldosterone secretion. Therefore, even though PA is statistically well correlated with PRA as was studied here, further study is required, such as measuring the hormones more frequently and investigating a central nervous system rhythm as suggested by Katz et al. (1975).

An obvious diurnal rhythm in PA was demonstrated in 3 of 5 cases of normotensive acromegaly. Although there was a significant positive partial correlation between PA and PC, PA was not significantly correlated with PRA. Moreover, no diurnal rhythm of PA was observed in 1 case which has no diurnal rhythm of PC. There was no apparent diurnal rhythm in PRA in normotensive acromegaly except in one case, while the diurnal rhythm in PC similar to that in normal subjects was observed in 3 of 4 cases. The reason for the absence of diurnal rhythm of PRA is not clear. The levels of PRA in acromegaly were lower than in normal subjects, probably as a result of the difference of age distribution. The normal control of the present series consisted of much younger subjects. However, the PRA levels of acromegaly on the fasting morning was not low by any means as compared with the generally accepted normal values. Therefore, it is not adequately conceivable that the absence of diurnal rhythm of PRA in the patients is the result of low PRA levels. On the other hand, the PA response to angiotensin-II infusion was significantly decreased in normotensive acromegaly as compared to that in the normal subjects. These findings may suggest that the aldosterone regulation system is slightly altered in some cases of normotensive acromegaly in contrast to that in the normal subjects in which PRA is thought to be the main contributing factor as described before. Two cases without obvious diurnal rhythm in PA were diagnosed as active acromegaly and widespread supraseller extension of the eosinophilic adenoma was demonstrated in one of them. Although there is a possibility that activity of acromegaly and/or wide extension of the tumor may have some close relationship to the absence of diurnal rhythm of PA, we have no decisive data at the present time in this regard.

The diurnal PA levels were decreased in 3 of 5 cases in normotensive acromegaly, though PRA levels were not low in all but one. Cain and his coworkers (1972) have reported the subnormal response of aldosterone secretion during sodium restriction in normotensive acromegaly in spite of normal rise in upright plasma renin activity. They have raised several possibilities as the underlying mechanism for this subnormal response of aldosterone secretion, such as defective action of angiotensin-II on adrenal receptor sites, direct inhibitory action of growth hormone on the adrenal gland and decreased metabolic clearance of aldosterone. It seems to be unlikely that the low PA levels in 3 cases of normotensive acromegaly in the present series were the result of direct inhibitory action of growth hormone on the adrenal gland, because there was 1 case in which high diurnal PA levels were observed in spite of elevated growth hormone levels. On the other hand, it may be possible that the low PA levels were the result of aging, because the patients of 
normotensive acromegaly were much older than the normal subjects (Flood et al., 1967). Further study is necessary to clarify the underlying mechanism of low PA levels in normotensive acromegaly. The subnormal responsiveness of PA to angiotensin-II in the present study may suggest defective action of angiotensin-II on the adrenal gland, though a possibility of minor defect in aldosterone synthesis is not excluded as pointed out by Cain and his coworkers (1972). The mechanism of subnormal response of PA to angiotensin-II infusion in spite of normal levels of PRA is uncertain. The absence of normal diurnal rhythm of PRA may in some way relate to this subnormal response. Furthermore, it is speculated that the normal diurnal stimulation of angiotensin-II may be necessary for normal function of the adrenal gland.

High PA levels were observed in 1 case of normotensive acromegaly, although PA levels were within normal range in others. It seems to be unlikely that high diurnal PA levels in this case were the result of excessive secretion of ACTH, because the diurnal PC levels in normotensive acromegaly were normal in the present series. Roginsky and his cowerkers (1966) have reported that the response of PC to ACTH and diurnal variation of PC levels were generally normal in acromegaly. A possibility that the high diurnal PA levels were the effect of unknown pituitary factor(s) could not be entirely ruled out in the above case (Palmore and Mulrow, 1967; Palmore et al., 1970).

\section{Acknowledgment}

The authors express their appreciation to Dr. K. Murata for reviewing the manuscript, and also wish to thank Dr. H. Takikawa and Dr. T. Matsuzawa for their valuable advice and Miss M. Okabe for her technical assistance, and Miss A. Sekiguchi for her secretarial services.

\section{References}

Balzer, R. and E. P. McCullagh (1959). Amer. J. Med. Sci. 237, 449.

Cain, J. P., H. Williams and R. G. Dluhy (1970). Clin. Res. 18, 527.

Cain, J. P., H. Williams and R. G. Dluhy (1972). J. Clin. Endocrinol. Metab. 34, 73.

Dluhy, R. G. and G. H. Williams (1969). Ibid. 29, 1319.

Flood, C., C. Gherondache, G. Pincus, J. F. Tait, S. A. S. Tait and S. Willoughby (1967). J. Clin. Invest. 46, 960.

Freund, J. E. (1960). Modern Elementary Statistics Maruzen Asian Edition p. 328.

Gordon, R. D., L. K. Wolfe, D. P. Island and G. W. Liddle (1966). J. Clin. Invest. 45, 1587.

Grim, C., J. Winnacker, T. Peters and G. Gilbert (1974). J. Clin. Endocrinol. Metab. 39, 247.

Hamwi, G. J., T. G. Skiliman and K. C. Tufts, Jr. (1960). Amer. J. Med. 29, 690.

Ichikawa, S., K. Murata and R. Shigiya (1974). Endocrinol. Japon. 21, 361.

Katz, F. H., P. Romfh and J. A. Smith (1972). J. Clin. Endocrinol. Metab. 35, 178.

Katz, F. H., P. Romfh and J. A. Smith (1975). Ibid. 40, 125.

Palnore, W. P. and P. J. Mulrow (1967). Science 158, 1482.

Palmore, W. P., R. Anderson and P. J. Mulrow (1970). Endocrinology 86, 728.

Roginsky, M. S., J. C. Shaver, and N. P. Christy (1966). J. Clin. Endocrinol. Metab. 26, 1101.

Snedecor, G. W. and W. G. Cochran Statistical methods. 6 ed. p. 57 (1967) (In Japanese).

Souadjian, J. W. and A. Shriger (1967). Amer. J. Med. Sci. 254, 629.

Strauch, G., M. B. Vallotton, Y. Touitou and H. Bricaire (1972). N. Engl. J. Med. 287, 795.

Strauch, G., M. B. Vallotton, Y. Touitou and H. Bricaire (1973). Ibid. 289, 808.

Vagnucci, A. H., R. H. McDonald, Jr., A. L. Drash and A. K. C. Wong (1974). J. Clin. Endocrinol. Metab. 38, 761.

Werning, C., U. Schweikert, D. Stiel, W. Vetter and W. Sigenthaler (1970). Klin. Wschr. 48, 1365.

Williams, G. H., L. I. Rose, R. G. Dluhy, D. McCaughn, P. I. Jagger, R. B. Hickler and D. P. Lauler (1970). Ann. Intern. Med. 72, 317.

Williams, G. H., J. P. Cain, R. G. Dluhy and R. H. Underwood (1972). J. Clin. Invest. 51, 1731. 